\title{
Inhibitory effects of agmatine on monoamine oxidase (MAO) activity: Reconciling the discrepancies
}

\author{
Loretta Mancinelli ${ }^{1}$, Francesco Ragonese ${ }^{1,2}$, Samuela Cataldi ${ }^{3}$, Maria Rachele Ceccarini ${ }^{3}$, \\ Rossana G. Iannitti ${ }^{1}$, Cataldo Arcuri ${ }^{2}$ and Bernard Fioretti ${ }^{1 *}$
}

\begin{abstract}
Agmatine has been functionally characterized as an important hormone and co-neurotransmitter in mammals. Given its ability in binding Imidazoline sites, a regolatory site of monoaminoxydase, it has been suggested to be involved in many neurological aspects. However, its inhibitory effect on this enzyme still remains an unanswered question. This present study is aimed to asses whether different experimental conditions could affect the agmatine action on monoaminoxydase activity. We demonstrate that the monoaminoxydase inhibition by agmatine is obtained under alkaline conditions and a long time of incubation. No inhibitiory action was found for shorter times of reaction at elevated $\mathrm{pH}$, or at neutral condition and long time of incubation. No inhibition was also detected by substituting the monoamineoxydase substrate tyramine with kynuramine, however, while in these conditions a remarkable inhibition was shown by two aminoxydase inhibitors tranylcypromine and idazoxan. Herein, we discuss a mechanism model and the functional consequences of agmatine action on monoaminoxydase.
\end{abstract}

Keywords: Agmatine, MAO inhibition, imidizoline receptors, co-neurotransmitters and neurological disorders

'Department of Chemistry, Biology and Biotechnologies, Via Elce di Sotto 8, University of Perugia, Italy

2Department of Experimental Medicine, Piazzale Gambuli 1, University of Perugia, Italy

${ }^{3}$ Department of Pharmaceutical Science, Via Fabretti 48, University of Perugia, Italy.

${ }^{*}$ Corresponding author: B. Fioretti

E-mail: bernard.fioretti@unipg.it

DOI: 10.2478/ebtj-2018-0016

\section{Introduction}

Agmatine is an endogenous polyamine derived in mammals from arginine by the arginine decarboxylase enzyme. Several physiological functions have been demonstrated for this polyamine (1), including the release of insulin, catecholamine and luteinizing hormone from beta cells, adrenal gland and hypothalamus, respectively, and the ability to inhibit glutamatergic transmission and nitric oxide production. Agmatine reduced the effect of naloxone-precipitated abstinence syndrome of morphine dependent rats (2), and displayed antiproliferative properties in smooth muscle cells and neuroprotection in neurons (3-5). Substantial evidence supports agmatine as a co-neurotransmitter given its presence in synaptic vesicles and its potassium and calcium -dependent release from neurons $(6,7)$. Agmatine has been shown to bind to the imidazoline binding site $I_{2}$ localized in mitocondrial outer membrane of liver, kidney and brain (8). Among the various $\mathrm{I}_{2}$ binding proteins identified there is the monoamino oxidases (MAO) (9-10). The $\mathrm{I}_{2}$ binding site displays a high sequence homology with a specific domain present on the monoamino oxidase- $\mathrm{B}$ (MAO-B), and shows the same molecular weight (11-13). Moreover, transfection of MAO into yeast results in coherent coexpression of $\mathrm{I}_{2}$ sites. Altogether, these data indicate that the $\mathrm{I}_{2}$ binding site is located on the MAO molecule and constirutes allosteric sites of these enzymes (14). Agmatine can thus represent an endogenous modulator of the MAO enzyme. There is however no dedicated study that conclusively shows the ability of agmatine to modulate the MAO activity, however the same information to this regard can be found in studies carried out to evaluate the modulation of MAO by imidazoline ligands.
(C) 2018 Authors. This work was licensed under the Creative Commons AttributionNonCommercial-NoDerivs 3.0 License. 
A dose dependent inhibition of MAO activity by agmatine, with an $\mathrm{IC}_{50}$ of $168 \mu \mathrm{M}$, was reported in liver homogenate by Raasch and co-workers using a kynuramine-based assay (14). Furthermore agmatine has been shown interact with the catalytic sites of human recombinant MAO-A, and inhibit $50 \%$ of the oxidation activity at $1 \mathrm{mM}$ (15). Contrasting observations were however observed in other studies where agmatine was found to weakly inhibit the MAO activity in rat brain $(16,17)$ and liver homogenates $(18)$. Although the lack of inhibitory effect of agmatine on MAO activity found by Holt and Becker (16) could be due to the low agmatine concentration used $(50 \mu \mathrm{M})$, this explanation cannot apply to the negative results obtained by Su et al., 2001, and by Ozaita et al., $1997(17,18)$, where the agmatine concentration was 1 and $10 \mathrm{mM}$, respectively. The reason of these conflicting results is thus still an undetermined, although the possibility exists that they can be due to differences in experimental conditions used in the studies mentioned above, namely the incubation time, $\mathrm{pH}$ and substrate used. In this study we verified whether the inhibitory action of agmatine on MAO activity is dependent on the experimental conditions and thus reconciling the different conclusions reached by the above citied authors.

\section{Material and Methods Sample Preparation}

Mitochondria were separated from livers of male SpragueDawley rats (Charles River, Germany; body weight about 400 g). Liver tissue was minced and homogenized in buffer $(1 / 4$ w/v) with a tissue potter $\left(1 \mathrm{~min}, 4^{\circ} \mathrm{C}, 800 \mathrm{upm}, 8\right.$ strokes $)$. The composition of buffer was $320 \mathrm{mM}$ saccharose, $2 \mathrm{mM}$ HEPES, pH 7 with $\mathrm{NaOH}$. Homogenate was centrifuged twice (10 $\mathrm{min}, 1500 \mathrm{~g}, 4^{\circ} \mathrm{C}$ ). The supernatant was recentrifuged (30 min, $8000 \mathrm{~g}, 4^{\circ} \mathrm{C}$ ), and the resulting pellet (mitochondria fraction) was resuspended in fresh buffer, aliquoted, and stored at $-80^{\circ} \mathrm{C}$ until used. The amount of protein present in this solution was determined with the Biorad method (19) with bovine serum albumin used as standard reference.

\section{Determination of MAO Activity \\ Kynuramine-based assay}

In this assay the MAO activity was performed at $25{ }^{\circ} \mathrm{C}$ in $50 \mathrm{mM}$ TRIS-HCl buffer, $220 \mu \mathrm{M}$ kynuramine and liver homogenate (protein $0.5 \mathrm{mg} / \mathrm{mL}$ ) as previously described $(14,1520)$. The $\mathrm{pH}$ of the buffer was set at 7.4 or 9.2 by the addition of small amounts of concentrated $\mathrm{HCl}$ or $\mathrm{NaOH}$. The reaction was started by adding kynuramine and stopped after 20 minutes by adding $\mathrm{NaOH}$ and $\mathrm{ZnSO} 4$ at a final concentration of 25 and $35 \mathrm{mM}$, respectively. After 5 minutes boiling, the mixture was centrifuged $\left(10 \mathrm{~min}, 10000 \mathrm{~g}, 4^{\circ} \mathrm{C}\right)$ and the supernatant was spectrophotometrically analyzed. The activity was calculated from the increase in absorbace at $330 \mathrm{~nm}$, due to the production of 4-hydroxyquinone. Inhibitors were added 5 or 60 minutes before kinuramine.

\section{Peroxidase-coupled assay}

The assay is based on the hydrogen peroxide production associated to MAO activity measured by peroxidase-coupled reaction as previously described $(21,22)$ The reaction buffer contained (final concentration) $200 \mu \mathrm{M}$ vanillic acid, 100 $\mu \mathrm{M} 4$-aminoantipyrine, $0.8 \mathrm{U} / \mathrm{mL}$ horseradish peroxidise, 50 $\mathrm{mM}$ potassium phosphate, liver homogenate (protein $0.5 \mathrm{mg}$ / $\mathrm{mL}), \mathrm{pH} 7.4$, and the assay was started by adding tyramine $(750 \mu \mathrm{M})$. The reaction was performed in 96 -well polystyrene microliterplates (Corning, NY) and monitored at $37^{\circ} \mathrm{C}$ from the absorbance change at $492 \mathrm{~nm}$ in a Labsystems Multiskan MS microplate reader. In some experiments the reaction was performed in vials, and the overall absorbance spectrum was obtained using a spectrophotometer (Varian). Absorbance measurements were performed every 10 minutes for 20-40 $\min$.

\section{Results}

Following the addition of MAO substrate tyramine, a significant MAO activity could be observed in rat liver homogenates. This was visualized by peroxidase-coupled assay following hydrogen peroxide production by MAO as indicated by the increase of peak of absorbance at $492 \mathrm{~nm}$ respect to no-tyramine condition (Fig. 1A and S1A).

The MAO activity was fully prevented by incubation with the MAO inhibitor tranylcypromine (10 $\mu \mathrm{M}$; Fig. 1A inset), with an $\mathrm{IC}_{50}$ of $756 \mathrm{nM}$ (Fig. 1SB). By contrast, application of $1 \mathrm{mM}$ agmatine did not induce any inhibitory effect on the MAO activity (red trace in Fig. 1A and inset). These data agree with several previous studies (16-18), but are at variance with others (14-15).

However, in both these studies, where an inhibitory effect of agmatine on MAO activity was observed $(14,15)$, kynuramine was used as substrate to assay the MAO activity. To verify the dependency on the substrate of agmatine action on MAO activity we repeated the test described above using the kynuraminebased assay (Fig. S2A). Incubation of liver homogenates with kynuramine resulted in an absorbance increase to $330 \mathrm{~nm}$ (as expected from its conversion into 4-idroxychinoline) that could be fully suppressed by saturating concentrations of tranylcypromine (Fig. 1B). We also found using the peroxidasecoupled assay, agmatine both at $100 \mu \mathrm{M}$ and $1 \mathrm{mM}$ still failed to inhibit the MAO activity (Fig. 1B and S2B). Under these conditions idazoxan, a ligand for the imidazoline I2 binding site $(15,18)$ dose-dependently inhibited the MAO activity $\left(\mathrm{IC}_{50}\right.$ and h of $365 \mu \mathrm{M}$ and 1.2 respectively, Fig. S2B).

We then verified whether incubation time and $\mathrm{pH}$, could influence agmatine inhibition action on MAO activity. We first changed the agmatine $(1 \mathrm{mM})$ incubation time, by increasing it to 60 minutes, while keeping the $\mathrm{pH}$ constant at 7.4.

Under these conditions no differences could be observed in the MAO activity, as compared to level measured with 5 min incubation time (Fig. 2A). No difference in the agmatine modulation of MAO activity was also found when we changed the $\mathrm{pH}$, and carried out the experiments at a $\mathrm{pH}$ of 9.2, while 

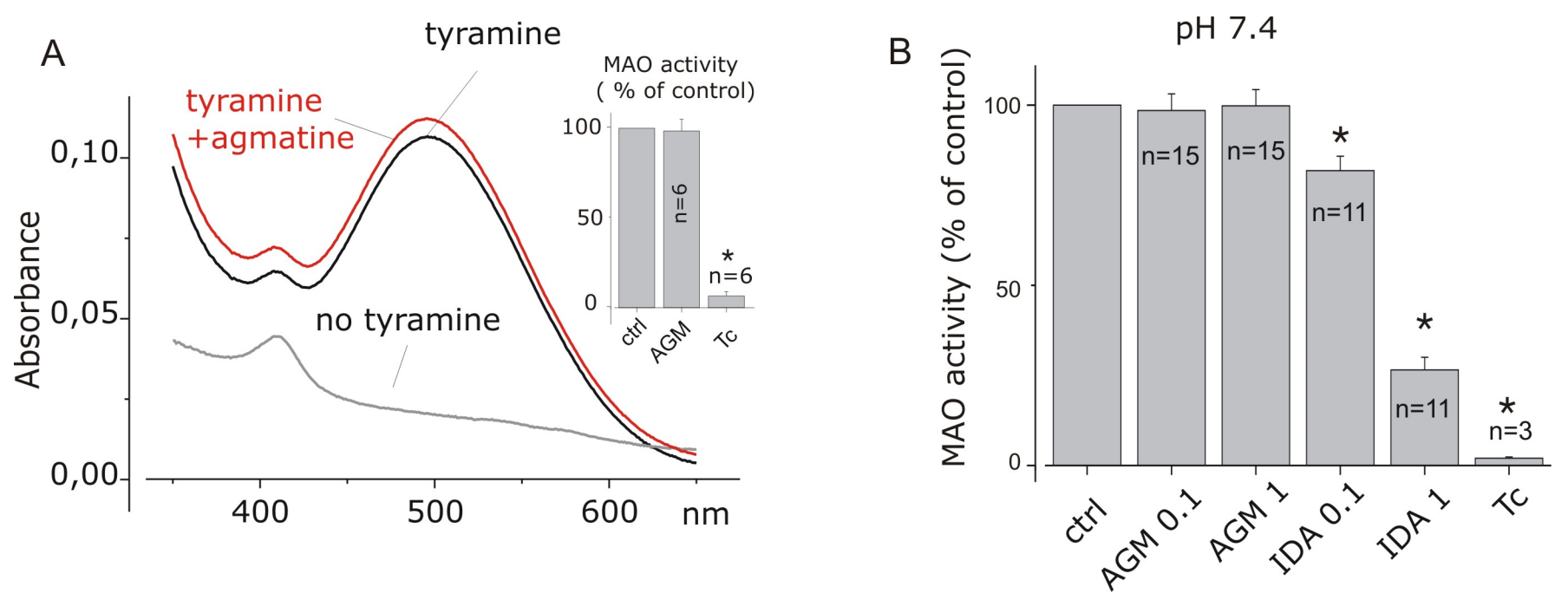

Figure 1. Agmatine does not inhibit liver MAO activity. A) Representative experiment showing the absorption spectra without (gray trace) and in presence of tyramine (black trace) or following co-application of $1 \mathrm{mM}$ of agmatine (red trace). MAO activity was monitored using the peroxidase-coupling assay $(750 \mu \mathrm{M}, \mathrm{pH} 7.4$ and $30 \mathrm{~min})$. Inset: bar plot showing the mean result of six experiments with tyramine in presence of either $1 \mathrm{mM}$ agmatine (AGM), or the MAO $10 \mu \mathrm{M}$ of MAO inhibitor tranylcypromine (Tc). AGM and Tc data are normalized with respect to control conditions. Normalization was also applied to SE using error propagation. B) Bar plot showing the mean effects of agmatine $(0.1$ and $1 \mathrm{mM})$, idazoxan $(0.1$ and $1 \mathrm{mM})$, and tranylcipromine $(3 \mu \mathrm{M})$ on MAO activity, determined with kinuramine-based assay (see Methods). The asterisk indicates the significant difference with respect to control $(p<0.05)$.

A

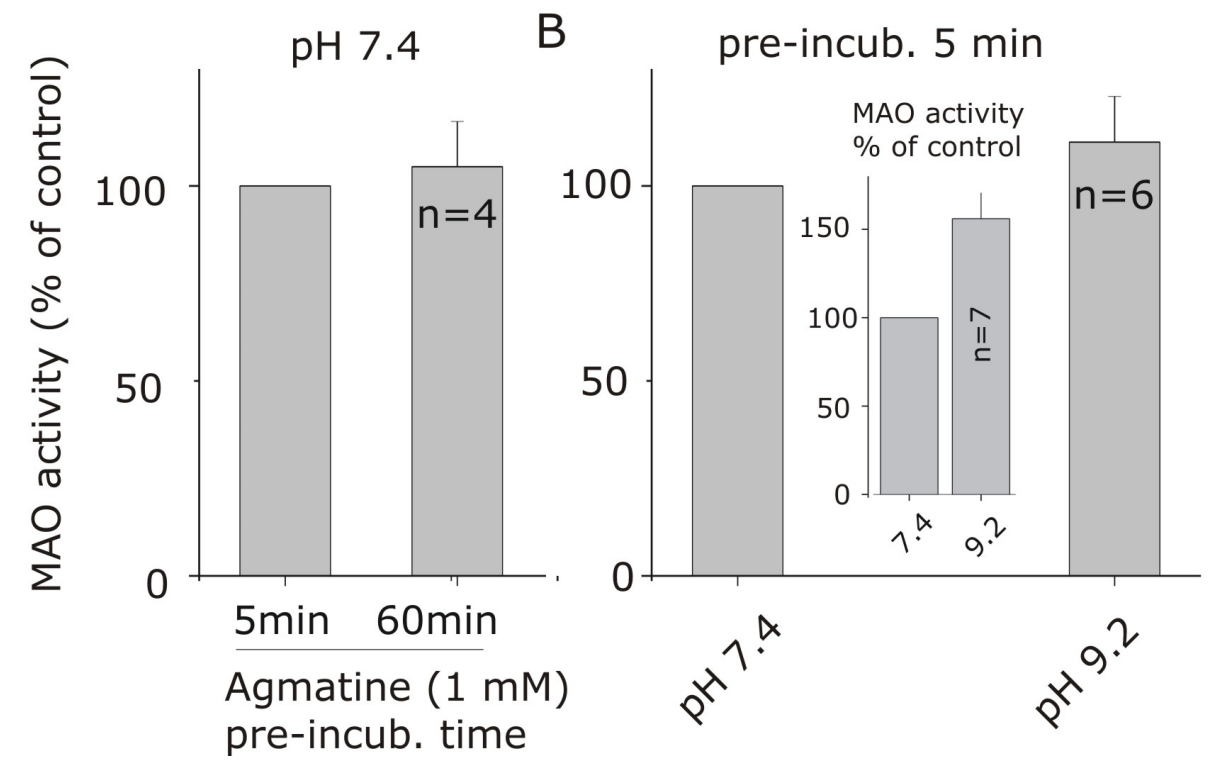

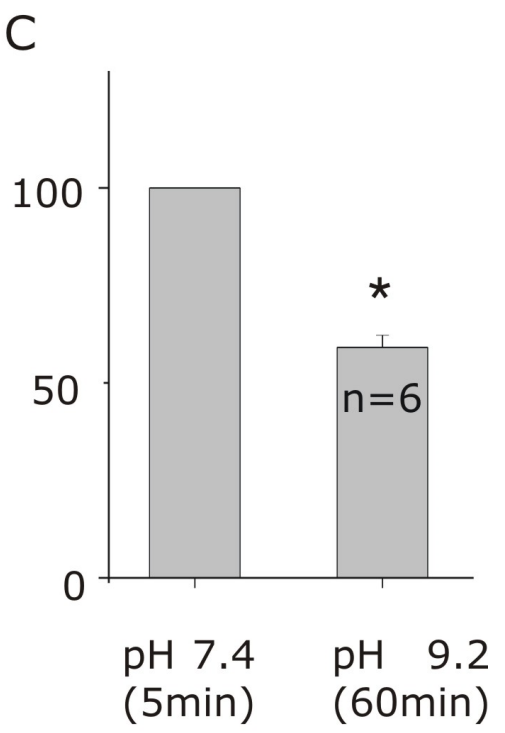

Figure 2. The inhibitory effect of agmatine on MAO activity depends on $\mathrm{pH}$ and incubation time. Bar plots showing the effect of 1 mM agmatine on MAO activity when: A) agmatine incubation time is increased to 60 minutes, while the pH is kept constant at 7.4; B) the $\mathrm{pH}$ is increased to 9.2, while incubation time is kept constant at $5 \mathrm{~min}$ (data showing the effect of agmatine on MAO activity are normalized to the MAO activity at the corresponding $\mathrm{pH}$ ). Inset shows the increased effect of MAO activity in alkaline condition as consequence of deprotonation of amine (kynuramine) substrate. $\mathrm{C}$ ) both agmatine incubation time and the $\mathrm{pH}$ are increased to 60 minutes and 9.2 respectively. The effects of agmatine $(1 \mathrm{mM})$ on MAO activity are given as compared to those obtained with kynuramine substrate at $\mathrm{pH} 7.4$ and agmatine incubation time fixed at $5 \mathrm{~min}$.

keeping the incubation time of agmatine constant at 5 minutes (Fig. 2B). To this regard it needs to be said that at $\mathrm{pH} 9.2$ we found a significant increase in MAO activity (inset Fig. 2B), as consequence of deprotonation of amine (kynuramine) substrate (14). By contrast, when the agmatine (1 mM) incubation time was increased to $60 \mathrm{~min}$, and simultaneously the $\mathrm{pH}$ was increased to 9.2, we observed a marked inhibition of the MAO activity by agmatine, which we failed to observe previously when we separately changed only one of these two conditions, namely incubation time and $\mathrm{pH}$ (Fig. 2C). 
A

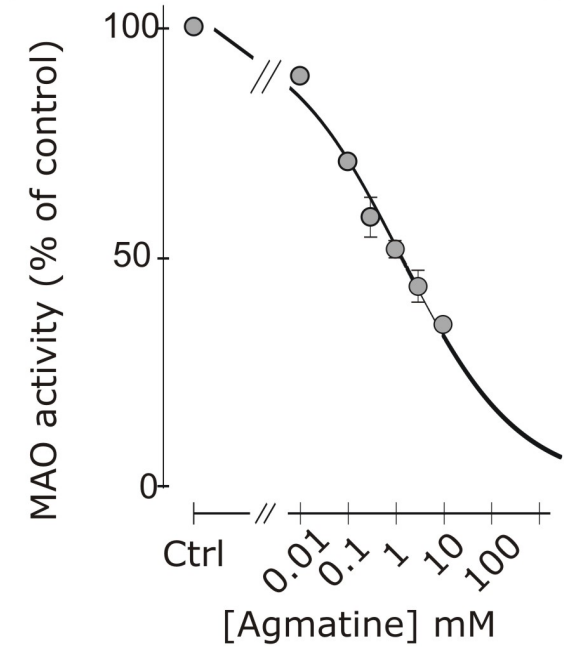

B

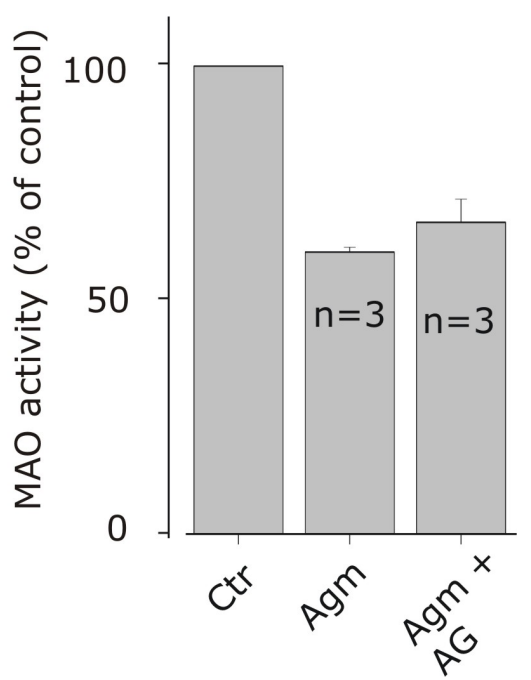

Figure 3. Proprerties of agmatine inhibition of MAO activity. A) Dose-response of agmatine inhibition of MAO activity at pH 9.2 after 60 min incubation. The curve represents the best fit with the Hill equation $100 /\left[1+\left([\text { Agmatine }] / I C_{50}\right)^{\mathrm{h}}\right]$ with $I C_{50}$ and $\mathrm{h}$ of $1.3 \mathrm{mM}$ and 0.35 , respectively. B) Bar plots showing the lack of the effect of aminoguanidine (AG, $1 \mathrm{mM})$ in preventing the inhibitory effects of $1 \mathrm{mM}$ agmatine on MAO activity.

We then investigated some features of agmatine inhibition on MAO activity under these experimental conditions (60 minutes incubation time and $\mathrm{pH}$ fixed at 9.2). Agmatine was able to inhibit the MAO activity in a dose-dependent manner (Fig. 3A) with $\mathrm{IC}_{50}$ and h (Hill's coifficent) of $1.3 \mathrm{mM}$ and 0.35 respectively, values similar to those reported by Raash et al. (14). The relatively long incubation time required for the agmatine inhibition of MAO activity raised the possibility that the accumulation of a agmatine metabolite was needed for the inhibitory effect. The two main agmatine metabolites known are putrescine, catalyzed by agmatinase, and 4-guanoglutaraldeide catalyzed by diamino oxidase (DAO) (14). Since putrescine has already been shown to be ineffective on MAO activity (14), under conditions similar to ours, we then verified the requirement of 4-guanoglutaraldeide for the agmatine dependent inhibition of MAO activity. For this purpose we added the DAO inhibitor aminoguanidine to agmatine in MAO mixture reaction (16). As shown in Fig. 3B, aminoguanidine at $1 \mathrm{mM}$ did not abolish the inhibitory effect of agmatine on liver MAO activity, suggesting that an enzymatic conversion of agmatine by DAO is not needed for its inhibitory effects.

\section{Discussion}

Our results indicate that the apparently contrasting conclusions previously reached with regard to the inhibitory efficacy of agmatine on MAO activity can be reconciled by taking into account the different experimental conditions used, namely differences in the agmatine incubation time and the $\mathrm{pH}$ of the milieu. More specifically, a significant inhibitory effect of MAO activity by agmatine is observed when both relatively long incubation times and high $\mathrm{pH}$ are used. A possible explanation for the experimental condition dependence in the agmatine MAO activity inhibition could be found in the change of conformational state of enzyme induced by experimental reaction conditions.

Note that a similar incubation time and $\mathrm{pH}$ dependency has been known for a long time, for example, in the studies involving hydrazine reagents as MAO inhibitors (23). In addition, MAO inhibitors such as $\beta$-carboline can inhibit the MAO activity depending on the incubation time (24), while oxazolidinones display a remarkable increased inhibitory potency in alkaline melieu (15).

Agmatine administration produced antidepressant-like behaviour in animal (25) and in human case studies (26) with a involvement of non-serotoninergic meccanism but with imidazolines receptors. Since MAO enzyme is an important target in anti-depressive drugs and associated to I2 imidazolines receptors, the inhibitory effect of agmatine in MAO activity here investigated might contribute to a greater understandment of the role of agmatine in the neurological disorders. However, further studies are need to conclusively define the inhibitory mechanism of agmatine on MAO activity and its involvement in pathophysiological states (27).

\section{Conflict of interest statement}

The authors declare that they have no conflict of interest.

\section{References}

1. Raacsh W, Schafer U, Chun J \& Dominiak P. Biological significance of agmatine, an endogenous ligand at imidazoline binding sites. Br J Pharmacol. 2001; 133, 755-780.

2. Aricioglu-kartal F \& Uzbay IT. Inhibitory effect of agmatine on naloxone-precipitated abstinence syndrome in morphine dependent rats. Life Sci.1997; 61, 1775-1881.

3. Regunathan S, Youngson C, RaascH W, Wang H \& Reis DJ. Imidazoline receptors and agmatine in blood vessels: a novel system inhibiting vascular smooth muscle proliferation. J Pharmacol Exp Ther. 1996; 276, 1272-1282. 
4. Gilad GM, Gilad VH \& Rabey JM. Arginine and ornithine decarboxylation in rodent brain: coincidental changes during development and after ischemia. Neurosi Lett 1996; 216, 33-36.

5. Olmos G, Degregorio-Rocasolano N, Paz RM, Gasull T, Assumpcio BM, Trullas R, Villarroel A, Lerma J \& Garcia-Sevilla JA. Protection by imidazol(ine) drugs and agmatine of glutamate-induced neurotoxicity in cultured cerebellar granule cells through blockade of NMDA receptor. Br J Pharmacol. 1999; 127,1317-1326.

6. Reis DJ \& Regunathan S. Is agmatine a novel neurotransmitter in brain? TiPS. 2000; 21, 187-193.

7. Goracke-Postle CJ, Overland AC, Riedl MS, Stone LS, Fairbanks CA. Potassium-and capsaicin-induced release of agmatine from spinal nerve terminals. J. Neurochem. 2007 Sep;102(6):1738-48.

8. Li G, Regunathan S, Barrow CJ, Eshraghi J, Cooper R, \& Reis DJ. Agmatine: an endogenous clonidine-displacing substance in the brain. Science. 1994; 263:966-9.

9. Tesson F, Prip-Buus C, Lemoine A, Pegorier JP, Parini A. Subcellular distribution of imidazoline-guanidinium-receptive sites in human and rabbit liver. Major localization to the mitochondrial outer membrane. J Biol Chem. 1991; 266:155-60.

10. Tesson F, Prip-Buus C, Lemoine A, Pegorier JP \& Parini A. Characterization of mitochondrial imidazoline-guanidinium receptive sites (IGRS) in liver. Am J Hypertens. 1995; 5, 805-825.

11. Raddatz R, Parini A \& Lanier SM. Localization of the imidazoline binding domain on monoamine oxidase. B Mol Pharmacol 1997; 52, 549-553.

12. Raddatz R, Savic SL, Bakthavachalam V, Lesnik J, Jasper JR, Mcgrath CR, Parini A, Lanier SM. Imidazoline-binding domains on monoamine oxidase $B$ and subpopulations of enzyme. J Pharmacol Exp Ther 2000; 292, 1135-1145.

13. Head GA, \& Mayorov DN. Imidazoline receptors, novel agents and therapeutic potential. Cardiovasc Hematol Agents Med Chem. 2006; 4:17-32.

14. Raasch W, Muhle H, \& Dominiak P. Modulation of MAO activity by imidazoline and guanidine derivatives. Ann N Y Acad Sci. 1999; 881:313-31.

15. Jones TZ, Giurato L, Guccione S. \& Ramsay RR. Interactions of imidazoline ligands with the active site of purified monoamine oxidase A. FEBS J. 2007; 274, 1567-1575.

16. Holt A. \& Baker GB. Metabolism of agmatine (clonidine-displacing substance) by diamine oxidase and the possible implications for studies of imidazoline receptors. Prog Brain Res. 1995; 106, 187197.

17. Su RB, Li J, Li X. \& Qin BY. Down-regolation of MAO-B activity and imidazoline receptors in rat brain following chromic treatment of morphine. Acta Pharmacol. Sin. 2001; 22, 639-644.

18. Ozaita A, Olmos G, Boronat MA, Lizcano JM, Unzeta M. \& GarciaSevilla JA. Inhibition of monoamine oxidase $A$ and $B$ activities by imidazol(ine)/guanidine drugs, nature of the interaction and distinction from 12-imidazoline receptors in rat liver. $\mathrm{Br} J$ Pharmacol. 1997; 121, 901-912.

19. Bradford MM. A rapid and sensitive method for the quantitation of microgram quantities of protein utilizing the principle of proteindye binding. Anal Biochem. 1976; 72:248-54.

20. Weissbach H, Smith TE, Daly JW, Witkop B, \& Udenfriend S. A rapid spectrophotometric assay of mono-amine oxidase based on the rate of disappearance of kynuramine. J Biol Chem. 1960; 235:1160-3.

21. Holt A, Palcic MM. A peroxidase-coupled continuous absorbance plate-reader assay for flavin monoamine oxidases, coppercontaining amine oxidases and related enzymes. Nat Protoc. 2006; 1(5):2498-505.

22. Holt A., Sharman D.F., Baker G.B., \& Palcic M.M. (1997). A continuous spectrophotometric assay for monoamine oxidase and related enzymes in tissue homogenates. Anal Biochem. 244:384-92.

23. Tipton KF. Inhibition of monoamine oxidase by substituted hydrazines. Biochem J. 1992; 128:913-9.

24. Kim H, Sablin SO, \& Ramsay RR. Inhibition of monoamine oxidase A by beta-carboline derivatives. Arch Biochem Biophys. 1997; 337:137-42.

25. Zomkowski AD, Hammes L, Lin J, Calixto JB, Santos AR, Rodrigues AL. Agmatine produces antidepressant-like effects in two models of depression in mice. Neuroreport. 2002; 13(4):387-91.

26. Shopsin B. The clinical antidepressant effect of exogenous agmatine is not reversed by parachlorophenylalanine: a pilot study. Acta Neuropsychiatr. 2013; 25(2):113-8. doi: 10.1111/j.16015215.2012.00675.x.

27. Laube G, Bernstein HG. Agmatine: multifunctional arginine metabolite and magic bullet in clinical neuroscience? Biochem J. 2017; 474(15):2619-2640. 
A

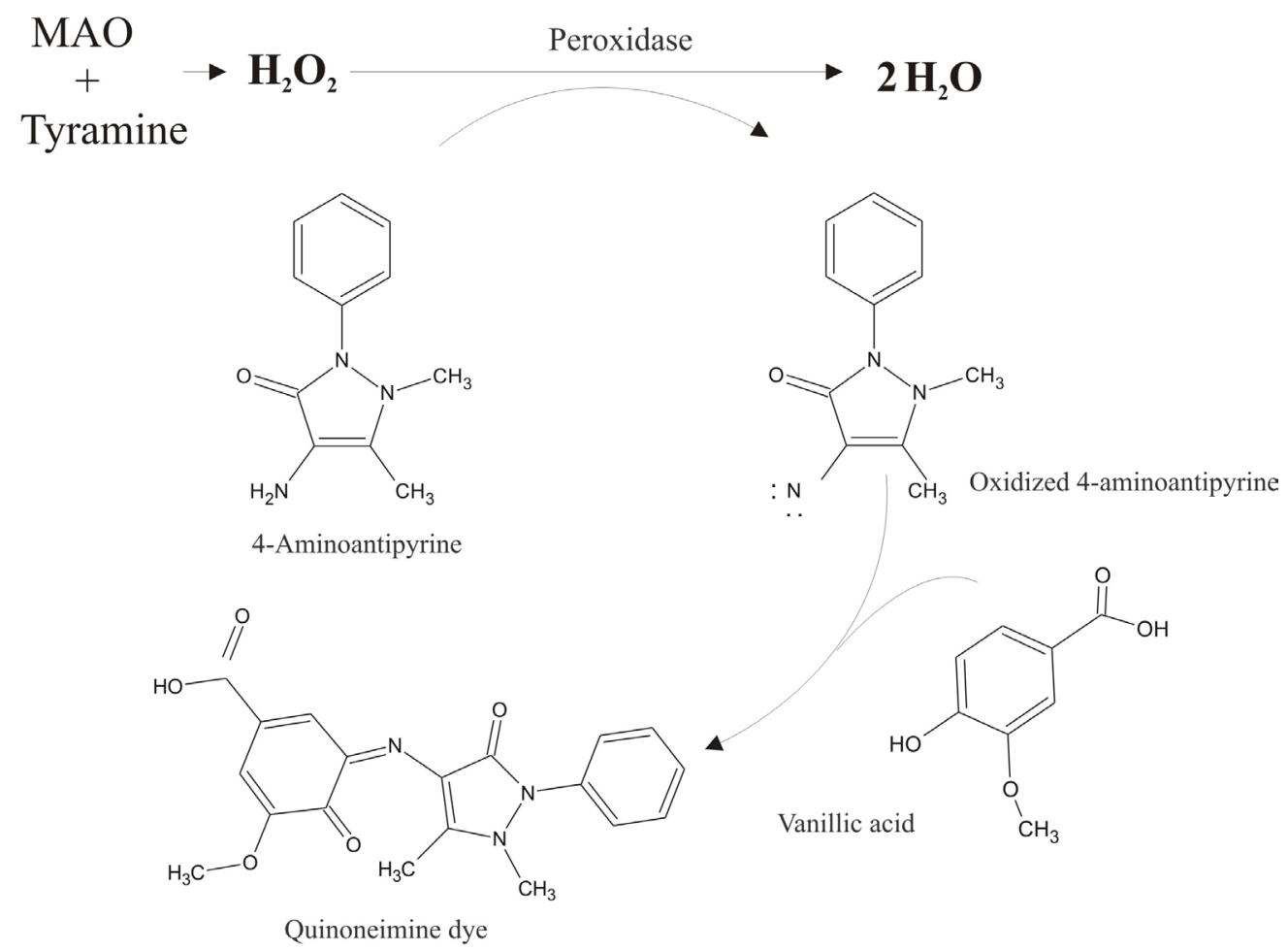

$\mathrm{B}$

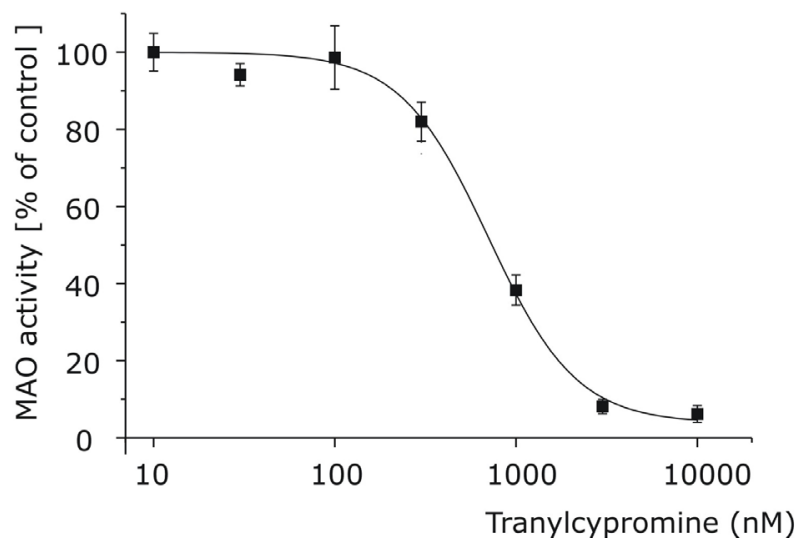

Figure 1S. A) Peroxidase-coupled assay scheme. Hydrogen peroxide derived from MAO enzyme activity, reacts with chromogenic mixture (4-Aminoantipyrine and vanillic acid) to generate a quinoneimine dye following peroxidase enzyme catalysis.

B) Tranylcypromine MAO inhibition estimated by peroxidase-coupled assay. The line represents the best fit with Hill equation providing values for IC50 of $760 \mathrm{nM}$ with a Hill coefficient of 1.8. Single data points represent a mean value \pm se $(n=6)$. 
A

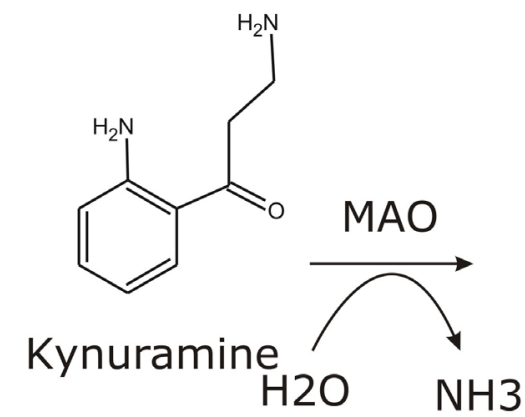<smiles>CCCCCCO</smiles><smiles>Oc1ccnc2ccccc12</smiles>

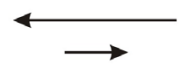<smiles>O=C1CC=Nc2ccccc21</smiles>

\section{4 hyidroxy-quiinoline}

B

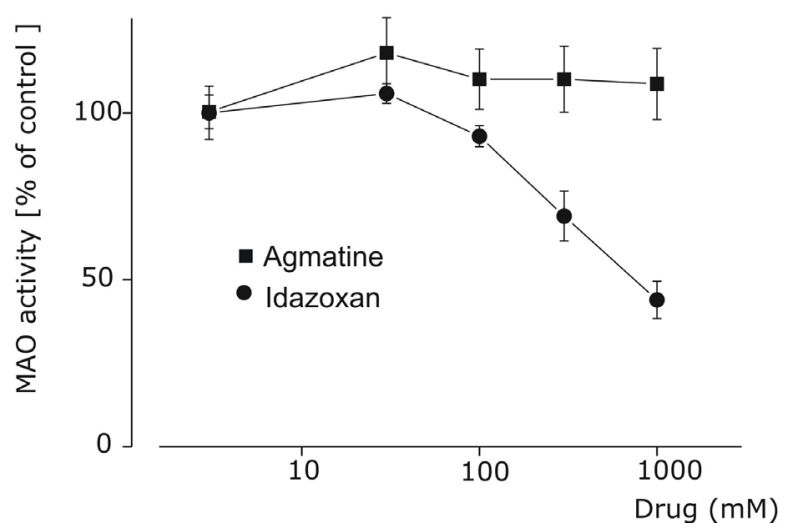

Figure 2S. A) Kynuramine-based assay scheme. Deamination of kynuramine catalyzed by MAO providing an aldehyde, followed by non-enzymatic condensation to 4-hydroxyquinoline. B) Dose- dependence inhibition of MAO at various concentration of agmatine (squares, range $0.003-1 \mathrm{mM}, \mathrm{n}=3$ ) and Idazoxan (circles, range $0.003-1 \mathrm{mM}, \mathrm{n}=3$ ). 